\title{
EDUCAÇÃO EM SAÚDE NO TRÂNSITO PARA ADOLESCENTES ESTUDANTES DO ENSINO MÉDIO
}

\author{
Health education activity about traffic for high school students \\ Educación en salud del tránsito para jóvenes estudiantes de la enseñanza media
}

Rafael Tavares Jomar ${ }^{1} \quad$ Marcelo Rodrigues Ribeiro ${ }^{2} \quad$ Ângela Maria Mendes Abreu ${ }^{3} \quad$ Rachel Ferreira Savary Figueirò ${ }^{4}$

\section{RESUMO}

Este é um relato de experiência de acadêmicos de enfermagem em uma atividade de Educação em Saúde no Trânsito que objetivou sensibilizar adolescentes estudantes de ensino médio quanto à relação perigosa do consumo de bebidas alcoólicas e os acidentes de trânsito. Aproximadamente 150 estudantes de 14 a 19 anos participaram da atividade, que foi composta por exibição de vídeo, palestra, discussão e distribuição de material educativo. Com esta experiência, os acadêmicos de enfermagem puderam vivenciar um trabalho de Extensão Universitária com enfoque na prevenção de agravos na comunidade e concluíram que o profissional enfermeiro pode desempenhar um papel importante na prevenção dos acidentes de trânsito envolvendo uso de álcool; entretanto, este tema precisa ser mais trabalhado durante sua formação.

Palavras-chave: Educação em Saúde. Acidentes de Trânsito. Consumo de Bebidas Alcoólicas. Transtornos Relacionados ao Uso de Álcool. Prevenção de Acidentes.

\section{Abstract}

This is a nursing students' experience in a health education activity about traffic aimed to sensitize young high school students about the dangerous relationship between alcohol consumption and traffic accidents. Approximately 150 students between 14's and 19 's participated in the activity, which was composed of video displaying, lecture, discussion, and distribution of educational material. With this experience, nursing students could experience a work of University Extension, focusing on disease prevention in the community and concluded that the professional nurse can act in an important role in the prevention of traffic accidents involving alcohol use; however, this issue needs to be more emphasized during their academic training.

Keywords: Health Education. Accidentes, Traffic. Alcohol Drinking. Alcohol-Related Disorders. Accident Prevention.

\section{Resumen}

Esta es una experiencia de estudiantes de enfermería en una actividad de Educación en Salud del Tránsito, para sensibilizar jóvenes estudiantes de la enseñanza media sobre la peligrosa relación de consumo de alcohol y accidentes de tránsito. Aproximadamente 150 estudiantes de 14-19 años participaron en la actividad que fue compuesta de exhibición de vídeo, conferencia, debate, y distribución de material educativo. Con esta experiencia, los estudiantes de enfermería pudieron experimentar una actividad de Extensión de la Universidad, centrándose en la prevención de enfermedades en la comunidad. La conclusión fue que el profesional de enfermería puede desempeñar un papel importante en la prevención de los accidentes de tránsito relacionados con el uso de alcohol; sin embargo, esta cuestión debe ser trabajada más durante su formación.

Palabras clave: Educación en salud. Accidentes de Tránsito. Consumo de Bebidas Alcohólicas. Trastornos Relacionados con Alcohol. Prevención de Accidentes.

\footnotetext{
${ }^{1}$ Aluno do $8^{\circ}$ período do Curso de Graduação de Enfermagem e Obstetrícia da Escola de Enfermagem Anna Nery da Universidade Federal do Rio de Janeiro (EEAN/UFRJ)Rio de Janeiro, RJ, Brasil. E-mail: rafaeljomar@yahoo.com.br, ${ }^{2}$ Aluno do $8^{\circ}$ período do Curso de Graduação de Enfermagem e Obstetrícia da EEAN/UFRJ. Rio de Janeiro, RJ, Brasil. E-mail: rodrigues_mribeiro@yahoo.com.br, ${ }^{3}$ Doutora em Enfermagem. Professora Adjunta do Departamento de Enfermagem de Saúde Pública (DESP) da EEAN/UFRJ. Rio de Janeiro, RJ, Brasil. E-mail: angelabreu@globo.com, ${ }^{4}$ Doutora em Enfermagem. Professora Adjunta do DESP da EEAN/UFRJ. Rio de Janeiro, RJ, Brasil. E-mail: rachelfig@terra.com.br
} 


\section{INTRODUÇÃO}

Os acidentes de trânsito e a violência em geral constituem uma verdadeira e urgente questão de Saúde Pública no mundo moderno. 0 aumento da morbimortalidade, devido à violência no trânsito, já é considerado uma epidemia, face à sua extensão e consequências para o indivíduo, para a família e para a sociedade. ${ }^{1}$

0 número de pessoas que morrem a cada ano vítimas de acidentes de trânsito, segundo a Organização Mundial de Saúde, é estimado em cerca de 1,2 milhões ${ }^{2}$, o que corresponde a $25 \%$ das causas externas de mortalidade no planeta. ${ }^{3}$ As estimativas apontam tendência crescente desses números, que deverão aumentar em $40 \%$ até o ano 2030, caso não sejam adotadas medidas preventivas efetivas a esse respeito, sobretudo nos países em desenvolvimento. ${ }^{4}$

No Brasil, entre as causas externas, os acidentes de trânsito representam a segunda maior causa de óbitos, estando atrás apenas de mortes por homicídios. A faixa etária mais acometida nesse tipo de acidente é a dos jovens, correspondendo a mais de $50 \%$ das mortes entre 15 e 44 anos. Entre crianças e adolescentes de 5 a 14 anos e jovens de 15 a 29 anos, os acidentes de trânsito constituem a segunda causa de mortalidade. ${ }^{2,5}$

Os acidentes de trânsito representam importante carga social, não apenas pelos óbitos e sequelas que causam, mas também por onerarem a sociedade com custos diretos e indiretos, valor anual estimado em $1 \%$ a $2 \%$ do produto interno bruto. ${ }^{6}$

No ano de 2001, no Brasil, considerando toda a área urbana, este tipo de acidente gerou um custo de ordem de $R \$$ 5,3 bilhões, custos estes que podem ser calculados desde os custos médico-hospitalares, danos ao veículo, perda de produção até o impacto familiar, entre outros. ${ }^{7}$

Nesse contexto, sabe-se que uma parcela importante dos acidentes de trânsito pode ser atribuída ao consumo excessivo de álcool. Estima-se que $70 \%$ dos casos fatais desses acidentes estão relacionados com o uso e abuso de bebidas alcoólicas. ${ }^{8-9}$

Muitas pesquisas nacionais sublinham a relevância da relação álcool e trânsito e reafirmam que o uso e abuso de bebidas alcoólicas ocupam lugar de destaque entre as causas de acidentes automobilísticos, além de ressaltarem que entre metade e um quarto dos acidentes com vítimas fatais estão associados ao uso do álcool. ${ }^{1,9-11}$

A Política Nacional sobre o Álcool, instituída no Brasil em maio de 2007, afirma que a sociedade deve colaborar com a adoção de medidas que atenuem e previnam os danos resultantes do consumo de álcool em situações específicas, tal como o transporte, e ainda ressalta que deve haver proteção dos segmentos populacionais vulneráveis ao consumo prejudicial dessa substância. ${ }^{12}$

Dessa forma, essa mesma Política tem como uma de suas diretrizes a inclusão de ações de prevenção ao uso de bebidas alcoólicas nas instituições de ensino, em especial nos níveis fundamental e médio ${ }^{12}$.

Diante do exposto e mediante o impacto da recente Lei 11.705 de 19 de junho de 2008, a "Lei Seca", que trata da proibição do consumo de bebida alcoólica por condutor de veículo automotor, instituindo a alcoolemia zero ${ }^{13}$, foi proposta pela equipe docente do Programa Curricular Interdepartamental XI (PCI XI) do Curso de Graduação de Enfermagem e Obstetrícia da Escola de Enfermagem Anna Nery da Universidade Federal do Rio de Janeiro (EEAN/UFRJ), aos alunos do referido Programa, a realização de uma atividade de Educação em Saúde no Trânsito sobre a temática com adolescentes estudantes do ensino médio.

A Educação em Saúde pode ser compreendida como um conjunto de saberes e práticas voltadas para a prevenção de doenças e promoção da saúde. Um recurso no qual o conhecimento científico produzido na área da saúde pelos profissionais que ali atuam atinge a vida cotidiana das pessoas por meio da compreensão dos fatores condicionantes do processo saúde-doença, oferecendo subsídios para a adoção de novos hábitos a saúde. ${ }^{14}$

Dessa forma, os processos educativos precisam ser vistos não apenas na perspectiva da possibilidade de gerar conhecimentos, mas, sobretudo, na dimensão humana e de melhoria da qualidade de vida e saúde das pessoas. ${ }^{14}$

Portanto, o objetivo deste trabalho é relatar a experiência de acadêmicos de enfermagem em uma atividade de Educação em Saúde no Trânsito com adolescentes estudantes de uma escola de ensino médio, visando compartilhar a experiência de trabalho da enfermagem na prevenção de acidentes de trânsito envolvendo álcool.

\section{CONTEXTUALIZANDO A ATIVIDADE EDUCATIVA}

O PCI XI, disciplina obrigatória para alunos do Curso de Graduação de Enfermagem e Obstetrícia do sétimo período da EEAN/UFRJ, desenvolve atividades curriculares, junto a um Projeto de Extensão da UFRJ, no Núcleo de Atenção Integrada ao Acidentado de Trânsito - NAIAT, que tem como um dos seus objetivos, no âmbito da prevenção de agravos e promoção da saúde, realizar ações de Educação em Saúde para a população jovem.

Assim, uma atividade de Educação em Saúde no Trânsito foi desenvolvida por acadêmicos de enfermagem do PCI XI, junto a adolescentes estudantes do ensino médio, tendo como finalidade a sensibilização deste público quanto aos problemas relacionados ao beber e dirigir, uma combinação perigosa, que traz sérias consequências, conforme já relatado.

Dessa forma, a Extensão Universitária como uma atividade acadêmica pode ser elaborada em um processo educativo, cultural e científico ar ticulado com o ensino 
e a pesquisa, de forma indissociável, colaborando para a ampliação da relação entre a Universidade e a sociedade, possibilitando, assim, a geração de novos saberes. ${ }^{15}$

\section{RELATANDO A EXPERIÊNCIA}

Inicialmente a coordenação do $\mathrm{PCI} X \mathrm{XI}$ entrou em contato com a Coordenação Pedagógica da instituição escolhida, uma instituição pública de ensino médio de grande porte na cidade do Rio de Janeiro - RJ a fim de propor uma Ação Educativa em Saúde no Trânsito. Através de contatos telefônicos e envio de convite oficial explicitando a finalidade da atividade educativa, foi acordada uma data para a realização da mesma, após o aceite da instituição.

A atividade aconteceu no dia 30 de setembro de 2008, durante o período da manhã, tendo como participantes 150 adolescentes escolares, na faixa etária compreendida entre 14 e 19 anos, regularmente matriculados na referida instituição. Os adolescentes foram liberados das aulas e convidados pela Coordenação Geral da instituição a participar de uma ação educativa em saúde intitulada "Lei Seca: radicalismo ou necessidade?", que aconteceu no auditório local com duração de aproximadamente 40 minutos.

No primeiro momento da atividade, foi utilizado como recurso audiovisual a exibição de um vídeo sonorizado elaborado pelos acadêmicos de enfermagem com imagens de acidentes de trânsito associados ao uso de bebidas alcoólicas, que culminaram na morte de jovens na cidade do Rio de Janeiro e que haviam sido muito divulgados pelos meios de comunicação cariocas e até nacionais.

Esta foi uma maneira encontrada por nós de sensibilizar os adolescentes para o problema abordado, apresentando-os à consequência mais danosa do binômio Álcool-Direção: a morte.

Após a exibição do vídeo, através de palestra com auxilio de data show, foram apresentadas as estatísticas cariocas, fluminenses e nacionais sobre a morbimortalidade no trânsito e sua associação com o uso e abuso de bebidas alcoólicas. Neste segundo momento da atividade, foi dada grande ênfase ao fato de que a faixa etária mais atingida pelo binômio Álcool-Direção é a dos jovens. ${ }^{2,5}$

Ressaltamos aqui a importância desta modalidade de atividade educativa para essa população, pois acreditamos que receber informações sobre a associação do uso e abuso de álcool à alta mor talidade provocada pelo trânsito pode levá-la à reflexão e a uma (possível) mudança de atitude a fim de diminuir os números atuais alarmantes de mortes no trânsito.

A atividade prosseguiu, ainda no formato de palestra, com a (re)apresentação da "Lei Seca"13 aos adolescentes. 0 objetivo de (re)apresentarmos tal lei partiu do pressuposto de que, a partir desta iniciativa, divulgaríamos sua necessidade, além de colaborarmos para que os participantes pudessem tornar-se agentes multiplicadores das informações contidas nela, tanto na escola quanto no bairro em que residem, ou mesmo em casa com suas famílias, contribuindo, assim, para a redução do número de acidentes de trânsito envolvendo álcool.

Também foi apresentada, durante a palestra, aos participantes da atividade a estratégia "Amigo da Vez". Esta estratégia consiste em eleger um integrante do grupo como - Amigo da Vez, que, em uma determinada ocasião, guiará o carro em segurança na volta para casa. Ou seja, o amigo eleito não poderá ingerir, nesta ocasião, bebidas alcoólicas, enquanto os outros integrantes poderão ingerir álcool, se assim quiserem.

Esta estratégia foi apresentada porque acreditamos em seu caráter responsável. Ela permite que pessoas que gostam de consumir álcool em seus programas de diversão não se sintam "punidos" com a "Lei Seca"13 e o consumam, se assim desejarem. No entanto, o consumo de álcool, neste caso, assume uma característica responsável, no sentido coletivo, pois, entregando as chaves de seu veículo a um amigo sóbrio, o indivíduo contribui para a redução do número de acidentes de trânsito envolvendo álcool, um grave problema de Saúde Pública. ${ }^{1}$

Antes do término da atividade foi distribuído aos adolescentes material educativo (em anexo) elaborado por nós com informações sobre a "Lei Seca"13, a estratégia "Amigo da Vez", efeitos do álcool no corpo humano, inclusive a longo prazo, com o propósito de que eles o distribuíssem em suas casas, bairros e também para os colegas de escola que não puderam participar da ação educativa.

Ao final da atividade foi aberta uma sessão de perguntas para os adolescentes que desejassem fazêlas. Neste momento, pôde ser observado que eles participaram dando depoimentos de pessoas próximas que perderam a vida em acidentes de trânsito e teceram comentários sobre a possibilidade do envolvimento de álcool no acidente.

\section{CONSIDERAÇÕES FINAIS}

A Intervenção Educativa descrita foi ao encontro das políticas de redução de danos no sentido de minimizar os riscos decorrentes do consumo de álcool ${ }^{13}$, ao levar aos adolescentes informações relevantes para apresentar o grave problema de Saúde Pública que são os acidentes de trânsito associados ao uso e abuso de álcool.

Com esta experiência os acadêmicos de enfermagem puderam vivenciar um trabalho de Extensão Universitária com enfoque na prevenção de agravos na comunidade, trabalho 
essencial à sua formação profissional, haja visto a grande inserção do enfermeiro em serviços de atenção primária à saúde, que vem remodelando suas práticas, além de sua inserção em escolas, planejando ações para o público adolescente.

Vale ressaltar, ainda, que essas atividades e experiências, como a relatada aqui, de realizar intervenções educativas junto a adolescentes estudantes do ensino médio, proporcionadas pelo $\mathrm{PCI} \mathrm{XI}$, têm levado os acadêmicos de Enfermagem à reflexão e à conclusão de que estamos diante de um importante e grande desafio, a redução da morbimortalidade relacionada aos acidentes de trânsito envolvendo o consumo de álcool, e que o profissional enfermeiro pode desempenhar um papel importante na prevenção desses acidentes. Entretanto, essa temática precisa ser trabalhada durante nossa formação.

Por fim, consideramos que somente com informação e educação, sobretudo para a população jovem, futuros motoristas e cidadãos do trânsito, isto será possível.
11.Abreu AMM, Lima JMB, Griep RH. Acidentes de transito e a freqüência dos exames de alcoolemia com vítimas fatais na cidade do Rio de Janeiro. Esc Anna Nery. 2009 jan/mar; 13(1): 44-50.

12. Decreto $n^{\circ} 6.117$, de 22 de maio de 2007. Aprova a Política Nacional sobre o Álcool, dispõe sobre as medidas de redução do consumo indevido de álcool e sua associação com a violência e criminalidade.

13. Lei $n^{\circ} 11.705$, de 19 de junho de 2008. Dispõe sobre a inibição do consumo de bebida alcoólica por condutor de veículo automotor.

14.Silva SED, Vasconcelos EV, Padilha MICS, Martini JG, Backes VMS. A educação em saúde como uma estratégia para Enfermagem na prevenção do alcoolismo. Esc Anna Nery. 2007; 11 (4): 699-705.

15.Ministerio da Educação(BR). Fórum de Pró-Reitores de Extensão das Universidades Públicas Brasileiras-FORPROEX. Grupo Técnico. Indissociabilidade ensino-pesquisa-extensão e a flexibilização curricular: uma visão da extensão. Porto Alegre(RS): UFRGS; 2006.

\section{REFERÊNCIAS}

1.Abreu AMM. Mortalidade nos acidentes de trânsito na cidade do Rio de Janeiro relacionada ao uso e abuso de bebidas alcoólicas [tese]. Rio de Janeiro (RJ): Escola de Enfermagem Anna Nery, Universidade Federal do Rio de Janeiro; 2006.

2.World Health Organization-WHO. World report on road traffic injury prevention. Geneva: WHO; 2004.

3.Peden M, McGee K, Sharma G. The injury chart book: a graphical overview of the global burden of injury. Geneva: WHO; 2002.

4.Mathers C, Loncar D. Update projections of global mor tality and burden of disease, 2002-2030: data sources, methods and results. Geneva: WHO; 2002.

5.Andrade SM, Mello Jorge MHP. Características das vítimas por acidentes de transporte terrestre em município da Região Sul do Brasil. Rev Saude Publica 2000; 34 (2): 149-56.

6.Marín L, Queiroz MS. A atualidade dos acidentes de trânsito na era da velocidade: uma visão geral. Cad Saude Publica. 2000; 16: 7-21.

7. Instituto de Pesquisa Econômica Aplicada- IPEA. Impactos sociais e econômicos dos acidentes de trânsito nas aglomerações urbanas: síntese da pesquisa. Brasília (DF); maio 2003.

8.Chalub M, Telles LEB. Álcool, drogas e crime. Rev Bras Psiquiatr. 2006; 28 (supl 2): 69-73.

9.Lima JMB. Alcoologia: uma visão sistêmica dos problemas relacionados ao uso e abuso do álcool. Rio de Janeiro (RJ); UFRJ/EEAN; 2003.

10.Pinski I, Laranjeira R. 0 fenômeno de dirigir alcoolizado no Brasil e no mundo: uma revisão de literatura. Rev. ABP-APAL 1998; 20 (4): 160-65.
Recebido em 05/03/2010 Reapresentado em 02/06/2010 Aprovado em 16/09/2010 